\title{
Outcomes of Redo Transcatheter Aortic Valve Implantation for Structural Valve Degeneration of Transcatheter Aortic Valve
}

\author{
Masaki Tsuda, MD; Isamu Mizote, MD, PhD; Yasuhiro Ichibori, MD, PhD; \\ Takashi Mukai, MD; Koichi Maeda, MD; Toshinari Onishi, MD; \\ Toru Kuratani, MD, PhD; Yoshiki Sawa, MD, PhD; Yasushi Sakata, MD, PhD
}

\begin{abstract}
Background: The outcome of redo transcatheter aortic valve (TAV) implantation (TAVI) is unknown for TAV structural valve degeneration (SVD). This paper reports the initial results of redo TAVI for TAV-SVD in Japanese patients.

Methods and Results: Of 630 consecutive patients, 6 (1.0\%) underwent redo TAVI for TAV-SVD (689-1,932 days after the first $T A V I)$. The first $T A V$ were $23-m m$ balloon-expandable valves $(B E V, n=5)$ and a $26-m m$ self-expandable valve $(S E V, n=1)$. All patients underwent multidetector computed tomography (MDCT) before redo TAVI, which showed first-TAV under-expansion (range, 19.1$21.0 \mathrm{~mm}$ ) compared with the label size. Two BEV and $4 \mathrm{SEV}$ were successfully implanted as second TAV, without moderate/severe regurgitation or 30-day mortality. One of 2 patients with a BEV-inside-BEV implantation had a high transvalvular mean pressure gradient post-procedurally $(34 \mathrm{mmHg})$ and required surgical valve replacement 248 days after the redo TAVI. This, however, was unnoted in patients with SEV implantation during redo TAVI. Planned coronary artery bypass grafting was concomitantly performed in 1 patient with a small sino-tubular junction and SEV-inside-SEV implantation because of the risk of coronary malperfusion caused by the first TAV leaflets. Five of the 6 patients survived during the follow-up period (range, 285-1,503 days).
\end{abstract}

Conclusions: Redo TAVI for TAV-SVD appears safe and feasible, while specific strategies based on MDCT and device selection seem important for better outcomes.

Key Words: Aortic regurgitation; Aortic stenosis; Redo transcatheter aortic valve implantation; Structural valve degeneration

$\mathbf{T}$ ranscatheter aortic valve implantation (TAVI) is an established treatment option for severe symptomatic native aortic valve stenosis. ${ }^{1-3}$ Early outcomes of TAVI have rapidly improved over the last decade, including decreased rates of intraprocedural complications and 30-day mortality. ${ }^{4}$ A report from the Placement of Aortic Transcatheter Valves (PARTNER) trial showed that the valve functions of the transcatheter aortic valve (TAV), evaluated on echocardiography, were well maintained for up to 5 years in both high and extreme surgical risk patients. ${ }^{\mathbf{5}}$ Structural valve degeneration (SVD) of TAV (TAV-SVD) requiring retreatment is notably rare, with reported incidence rates of $0-0.6 \%$ during the 5 -year followup after TAVI. ${ }^{5-7}$ The number of redo TAVI, however, is expected to increase, with the currently increasing number of TAVI worldwide and as the indication for TAVI has been continuously broadened to patients with a longer life expectancy. Nonetheless, very few studies have shown the feasibility and outcomes of redo TAVI for TAV-SVD to date. Moreover, no data are available on Asian patients, who have a smaller aortic anatomy than Western patients. ${ }^{8}$ In the first Japanese trial using SAPIEN XT (Edwards Lifesciences, Irvine, CA, USA), the Transfemoral and Transapical Placement of Aortic Balloon Expandable Transcatheter Valve Trial (PREVAIL JAPAN), a 23-mm TAV was used in $71.9 \%$ of patients, while only $28.1 \%$ of patients received a 26-mm TAV. ${ }^{9}$ This may have caused suboptimal clinical outcomes of redo TAVI in Japanese patients because a high residual transvalvular mean pressure gradient ( $\mathrm{mPG} ;>20 \mathrm{mmHg}$ ) is often observed in TAVI for small degenerative surgical aortic bioprosthesis, and is associated with higher mortality after the procedure. ${ }^{10,11}$ Hence, in the current study, we report the initial results of redo TAVI for TAV-SVD to evaluate the safety and feasibility of this procedure in Japanese patients.

\author{
Methods \\ Patients \\ Between October 2009 and June 2018, 630 consecutive
}

Received December 7, 2018; revised manuscript received January 15, 2019; accepted January 16, 2019; J-STAGE Advance Publication released online February 15, 2019 Time for primary review: 1 day

Department of Cardiovascular Medicine (M.T., I.M., Y.I., T.M., T.O., Y. Sakata), Department of Cardiovascular Surgery (K.M., T.K., Y. Sawa), Osaka University Graduate School of Medicine, Suita, Japan

Mailing address: Isamu Mizote, MD, PhD, Assistant Professor, Cardiovascular Medicine, Osaka University Graduate School of Medicine, 2-2 Yamada-oka, Suita 565-0871, Japan. E-mail: i-mizote@cardiology.med.osaka-u.ac.jp

ISSN-2434-0790 All rights are reserved to the Japanese Circulation Society. For permissions, please e-mail: cr@j-circ.or.jp 


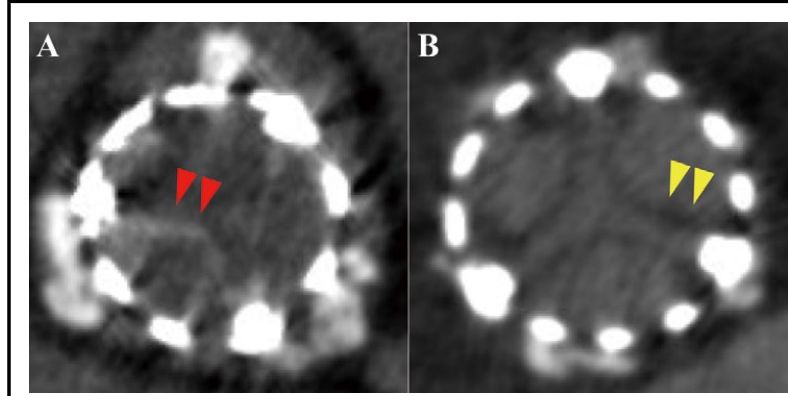

Figure 1. Multidetector computed tomography of structural valve degeneration of a transcatheter aortic valve. (A) Leaflet calcification (red arrowheads) and (B) leaflet thickening (yellow arrowheads).

patients underwent TAVI at Osaka University Hospital. We retrospectively reviewed patients who had undergone redo TAVI because of SVD of the initial TAV. We defined redo TAVI as a second procedure that involved implanting an additional TAV inside the initial one. The indication for redo TAVI was defined as symptomatic SVD, and all patients with symptomatic SVD underwent redo TAVI. SVD was diagnosed according to the definition of the Valve-in-Valve International Data report: briefly, both moderate stenosis and moderate regurgitation (SVD stage $2 \mathrm{RS}$ ), and severe stenosis or severe regurgitation (SVD stage 3) of TAV detected on transthoracic echocardiography or transesophageal echocardiography (TEE) were defined as SVD. ${ }^{12}$ Two patients who underwent redo TAVI because of device malposition early after the first TAVI were excluded from the SVD cohort. No patients underwent redo TAVI because of paravalvular regurgitation, TAV thrombosis, or infective endocarditis. Multi-detector computed tomography (MDCT) was also used to support the diagnosis of SVD (Figure 1). This study was conducted after the approval of the Institutional Review Board, because redo TAVI was not approved in Japan. Redo TAVI was performed as off-label use of balloon-expandable valves (BEV) or self-expandable valves (SEV) after receiving written informed consent from all patients in the study. In terms of second TAV device selection, BEV was used in the initial 2 cases, because SEV was not approved in Japan at the beginning of this study.

\section{Redo TAVI}

All redo TAVI procedures were performed under general anesthesia and TEE guidance using commercially available valves in Japan, that is, BEV (SAPIEN, SAPIEN XT; Edwards Lifesciences) or SEV (CoreValve, Evolut R; Medtronic, Minneapolis, MN, USA) via the transfemoral or direct aortic approach. All patients underwent 4-D MDCT before the redo TAVI. The second TAV size was determined by the stent internal diameter of the first TAV measured at the native aortic annulus level (Figure 2), in order to avoid annulus rupture or newly implanted TAV dysfunction. For crossing the first TAV, TEE was utilized to confirm that the guidewire had passed through the correct position of the first TAV. The implantation landmark of the second TAV was the bottom edge of the first TAV on fluoroscopy (Figure 2).

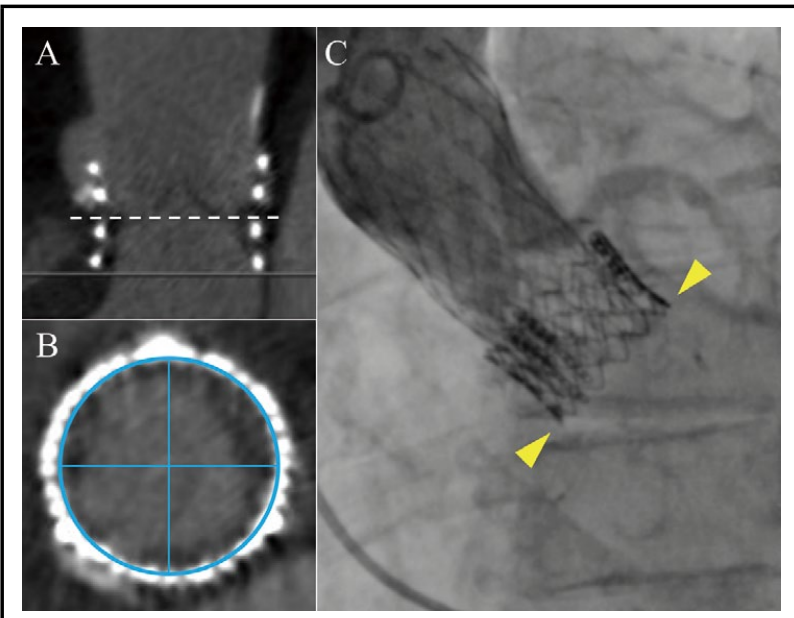

Figure 2. Multidetector computed tomography for preprocedural planning. (A) Native annulus level (----) in the stretched aortic root. (B) Measurement of the perimeter and average diameter of the first transcatheter aortic valve (TAV; inside stent line) using the cross-sectional image at the native annulus level. (C) Post-implantation angiography of redo TAV implantation showing a 26-mm Evolut R implantation inside a 23-mm Edwards-SAPIEN. Yellow arrowheads, bottom line of the first 23-mm Edwards-SAPIEN valve. No aortic regurgitation was observed.

\begin{tabular}{|c|c|c|}
\hline & $\begin{array}{c}\text { TAV-SVD } \\
\text { patients }(n=6)\end{array}$ & $\begin{array}{c}\text { Non-TAV-SVD } \\
\text { patients }(n=624)\end{array}$ \\
\hline Age (years) & $84(70-89)$ & $84(80-87)$ \\
\hline Female & $4(66.7)$ & $406(65.1)$ \\
\hline Diabetes mellitus & $1(16.7)$ & $190(30.4)$ \\
\hline COPD & $1(16.7)$ & $146(23.4)$ \\
\hline Previous stroke & $1(16.7)$ & $114(18.3)$ \\
\hline Previous MI & $1(16.7)$ & $77(12.4)$ \\
\hline Previous CABG & $1(16.7)$ & $67(10.7)$ \\
\hline PAD & $2(33.3)$ & $189(30.3)$ \\
\hline $\mathrm{AF}$ & $0(0)$ & $103(16.5)$ \\
\hline CKD & $6(100)$ & 457 (73.2) \\
\hline Chronic dialysis & $3(50.0)$ & $55(8.8)$ \\
\hline Liver cirrhosis & $0(0)$ & $41(6.6)$ \\
\hline NYHA III/IV & $4(66.7)$ & $273(43.8)$ \\
\hline Malignancy & $0(0)$ & $13(2.1)$ \\
\hline Previous pacemaker & $0(0)$ & $42(6.7)$ \\
\hline STS score (\%) & $8.6(5.8-22.5)$ & $7.8(5.4-11.3)$ \\
\hline LVEF (\%) & $61(38-70)$ & $65(55-73)$ \\
\hline Aortic gradient $(\mathrm{mmHg})$ & $43(37-80)$ & $45(38-57)$ \\
\hline
\end{tabular}

Data given as mean (range) or $\mathrm{n}(\%)$. $\mathrm{AF}$, atrial fibrillation; $\mathrm{CABG}$, coronary artery bypass graft; CKD, chronic kidney disease; COPD, chronic obstructive pulmonary disease; LVEF, left ventricular ejection fraction; MI, myocardial infarction; NYHA, New York Heart Association; PAD, peripheral artery disease; STS, Society of Thoracic Surgeons; SVD, structural valve degeneration; TAV, transcatheter aortic valve; TAVI, transcatheter aortic valve implantation. 


\begin{tabular}{|c|c|c|c|c|c|c|c|c|c|c|c|c|c|c|c|c|c|}
\hline \multirow{2}{*}{\multicolumn{2}{|c|}{$\begin{array}{l}\text { Patient } \\
\text { ID no. }\end{array}$}} & \multicolumn{2}{|c|}{$\begin{array}{c}\begin{array}{c}\text { Age } \\
\text { (years) }\end{array} \\
\end{array}$} & \multicolumn{2}{|c|}{ First TAVI } & \multicolumn{2}{|c|}{$\begin{array}{l}\text { MDCT before } \\
\text { redo TAVI }\end{array}$} & \multirow{2}{*}{$\begin{array}{c}\text { Reason } \\
\text { for redo } \\
\text { TAVI }\end{array}$} & \multicolumn{2}{|c|}{ Redo TAVI } & \multicolumn{2}{|c|}{$\begin{array}{c}\text { Peak velocity } \\
(\mathrm{m} / \mathrm{s})\end{array}$} & \multicolumn{2}{|c|}{$\begin{array}{c}\text { Mean PG } \\
(\mathrm{mmHg})\end{array}$} & \multicolumn{2}{|c|}{$\begin{array}{c}\text { iEOA } \\
\left(\mathrm{cm}^{2} / \mathrm{m}^{2}\right)\end{array}$} & \multirow[b]{2}{*}{ AR } \\
\hline & & $\begin{array}{l}\text { First } \\
\text { TAVI }\end{array}$ & $\begin{array}{l}\text { Redo } \\
\text { TAVI }\end{array}$ & Access & Device & $\begin{array}{c}\text { Perimeter } \\
\text { at NAL } \\
(\mathrm{mm})\end{array}$ & $\begin{array}{c}\text { Average } \\
\text { diameter } \\
\text { at NAL } \\
(\mathrm{mm})\end{array}$ & & Access & Device & $\begin{array}{c}\text { Before } \\
\text { Redo } \\
\text { TAVI }\end{array}$ & $\begin{array}{l}\text { After } \\
\text { Redo } \\
\text { TAVI }\end{array}$ & $\begin{array}{c}\text { Before } \\
\text { Redo } \\
\text { TAVI }\end{array}$ & $\begin{array}{l}\text { After } \\
\text { Redo } \\
\text { TAVI }\end{array}$ & $\begin{array}{c}\text { Before } \\
\text { Redo } \\
\text { TAVI }\end{array}$ & $\begin{array}{l}\text { After } \\
\text { Redo } \\
\text { TAVI }\end{array}$ & \\
\hline 1 & $H D$ & 76 & 78 & TF & $\begin{array}{c}\text { ES } \\
23-\mathrm{mm}\end{array}$ & 66.7 & 21.0 & AS & TF & $\begin{array}{c}\text { SXT } \\
23-m m\end{array}$ & 4.9 & 3.8 & 62 & 34 & 0.31 & 0.79 & Mild \\
\hline 2 & $\begin{array}{l}\text { Non } \\
\text { HD }\end{array}$ & 83 & 88 & TA & $\begin{array}{c}\text { SXT } \\
23-\mathrm{mm}\end{array}$ & 63.3 & 20.3 & AS & TF & $\begin{array}{c}\text { SXT } \\
23-\mathrm{mm}\end{array}$ & 4.3 & 2.8 & 41 & 17 & 0.65 & 1.04 & Mild \\
\hline 3 & $\begin{array}{l}\text { Non } \\
\text { HD }\end{array}$ & 86 & 91 & TI & $\begin{array}{c}\text { ES } \\
23-m m\end{array}$ & 63.4 & 20.3 & AR & TF & $\begin{array}{c}\text { ER } \\
26-\mathrm{mm}\end{array}$ & 2.4 & 1.5 & 13 & 5 & 0.85 & 1.07 & None \\
\hline 4 & $\begin{array}{l}\text { Non } \\
\text { HD }\end{array}$ & 89 & 94 & TS & $\begin{array}{c}\text { CV } \\
26-\mathrm{mm}\end{array}$ & 66.3 & 20.9 & AR & DA & $\begin{array}{c}\text { ER } \\
26-\mathrm{mm}\end{array}$ & 1.0 & 1.7 & 7 & 7 & 1.38 & 1.24 & None \\
\hline 5 & $\mathrm{HD}$ & 84 & 87 & TA & $\begin{array}{c}\text { SXT } \\
23-\mathrm{mm}\end{array}$ & 61.5 & 19.6 & $A S+A R$ & TF & $\begin{array}{c}\text { ER } \\
23-\mathrm{mm}\end{array}$ & 3.6 & 1.9 & 27 & 8 & 0.72 & 1.05 & Mild \\
\hline 6 & $\mathrm{HD}$ & 70 & 73 & TA & $\begin{array}{c}\text { SXT } \\
23-\mathrm{mm}\end{array}$ & 63.3 & 20.2 & AS & TF & $\begin{array}{c}\text { ER } \\
26-\mathrm{mm}\end{array}$ & 4.5 & 2.6 & 50 & 15 & 0.53 & 0.87 & Mild \\
\hline
\end{tabular}

AR, aortic regurgitation; AS, aortic stenosis; CV, CoreValve; DA, direct aorta; ER, Evolut R; ES, Edwards-SAPIEN; HD, hemodialysis; iEOA, index effective orifice area; MDCT, multidetector computed tomography; NAL, native annulus level; PG, pressure gradient; SXT, SAPIEN XT; TA, transapical; TAVI, transcatheter aortic valve implantation; TF, transfemoral; TI, transiliac; TS, transubclavian.

\section{Baseline, Follow-up Data, and Endpoint Definitions}

Baseline clinical, echocardiographic, and procedural details were recorded for all patients. All outcomes were defined according to the second report of the Valve Academic Research Consortium (VARC-2) criteria. ${ }^{13}$ The functions of the second TAV were assessed post-procedurally (inhospital) and at 30 days, 6 months, and 1 year after the redo TAVI according to published guidelines. ${ }^{14}$ Patientprosthesis mismatch (PPM) was assessed according to the VARC-2 criteria using the indexed effective orifice area (iEOA); iEOA <0.65 was considered severe PPM. High residual transvalvular $\mathrm{mPG}$ following redo TAVI was defined as $>20 \mathrm{mmHg}$.

\section{Statistical Analysis}

Continuous variables are described as median (range) or median (IQR). Categorical variables are described as absolute number and percentage. All statistical analyses were performed using JMP Pro 14.0 (SAS Institute, Cary, NC, USA).

\section{Results}

\section{Patient Characteristics and MDCT}

A total of 7 patients $(1.1 \%)$ had TAV-SVD during the median follow-up period of 602 days (IQR, 270-1,136 days; 6 symptomatic and 1 asymptomatic). The 6 patients with symptomatic TAV-SVD $(1.0 \%)$ underwent redo TAVI for TAV-SVD after the first redo TAVI was performed in March 2014. Three of the 6 patients received chronic dialysis $(50.0 \%)$. The prevalence of SVD was $5.6 \%$ with chronic dialysis ( $\mathrm{n}=58$; median follow-up, 376 days; IQR, 192-726 days), but was $0.5 \%$ for non-chronic dialysis $(n=572$; median follow-up, 717 days; IQR, 287-1,151 days). Baseline characteristics and echocardiographic data at the first TAVI are reported in Table 1. The prevalence of chronic dialysis tended to be higher in TAV-SVD patients than non-TAV-SVD patients. The median Society of Thoracic Surgeons score at redo TAVI was $15.5 \%$ (range, 10.8 $64.4 \%$, the first TAVI was not included as a patient-related operative risk factor). SVD type was as follows: stenosis in
3 patients (50.0\%), regurgitation in 2 patients $(33.3 \%)$, and both stenosis and regurgitation in 1 patient $(16.7 \%)$. Five 23-mm BEV and one 26-mm SEV were used in the first TAVI procedures. No patient had a high residual transvalvular $\mathrm{mPG}$, severe PPM, or moderate/severe aortic regurgitation immediately after the first TAVI. The median interval between the first and the redo TAVI was 1,487 days (range, 689-1,932 days).

On MDCT analysis before the redo TAVI, calcification was detected on the first TAV leaflets in 5 patients $(83.3 \%)$, except for 1 patient in whom lone regurgitation was detected as the cause of SVD. The leaflets were thickened in 4 patients $(66.7 \%)$. During follow-up, no patient had leaflet thrombosis, which was diagnosed based on previous reports. ${ }^{15,16}$ The median stent internal diameter of the first TAV was $20.3 \mathrm{~mm}$ (range, 19.1-21.0 mm), measured at the native aortic annulus level (Table 2). On preoperative MDCT the first TAV were expanded smaller than the label size in all patients. In 1 patient, who had a 26-mm CoreValve implanted at the first TAVI, preoperative MDCT also showed that the patient had a small sino-tubular junction (STJ), and it was anticipated that the leaflets of the first SEV would hamper blood flow to the coronary arteries following the second SEV implantation (Figure 3).

\section{Redo TAVI Procedural and Clinical Outcomes}

Procedural data for the first and the redo TAVI are reported in Table 2. The first 2 patients had a second BEV of an identical size $(23 \mathrm{~mm})$ implanted inside the first BEV. After these 2 cases, only SEV were used as a second TAV. Redo TAVI was mainly performed via the transfemoral approach $(n=5 ; 83.3 \%)$, while 1 patient underwent implantation via the direct aortic approach. The median volume of contrast media used for the redo TAVI was $25 \mathrm{~mL}$ (range, $5-104 \mathrm{~mL}$ ). In 1 patient with small STJ as described in the previous section, planned off-pump coronary artery bypass grafting $(\mathrm{CABG})$ was performed in conjunction with the redo TAVI because of a high possibility of coronary malperfusion.

Device success was achieved in 5 patients $(83.3 \%)$. The cause of device failure in 1 patient was a high residual 
A

(a)

(b)

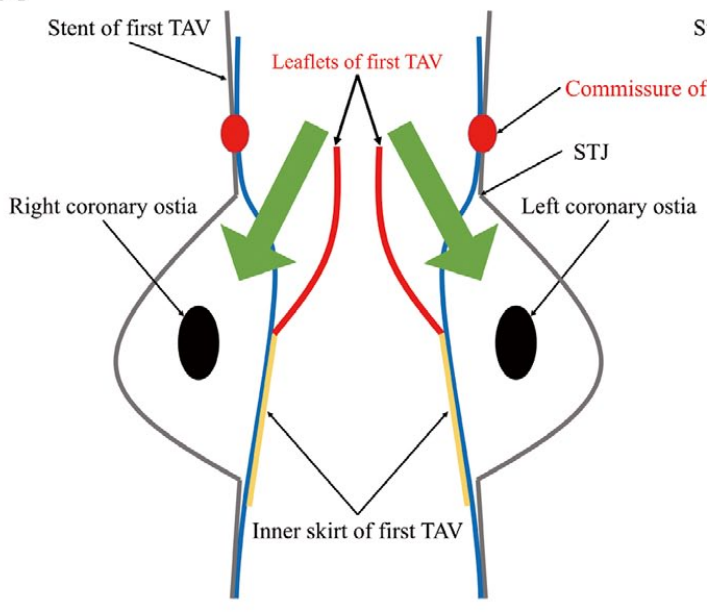

Before redo TAVI

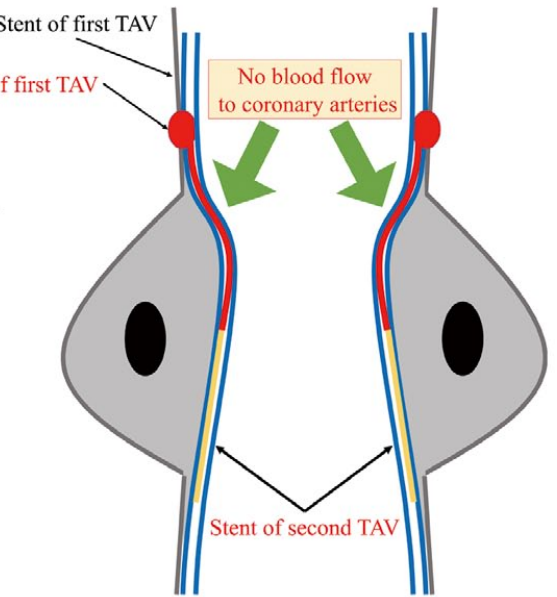

After redo TAVI

\section{B}

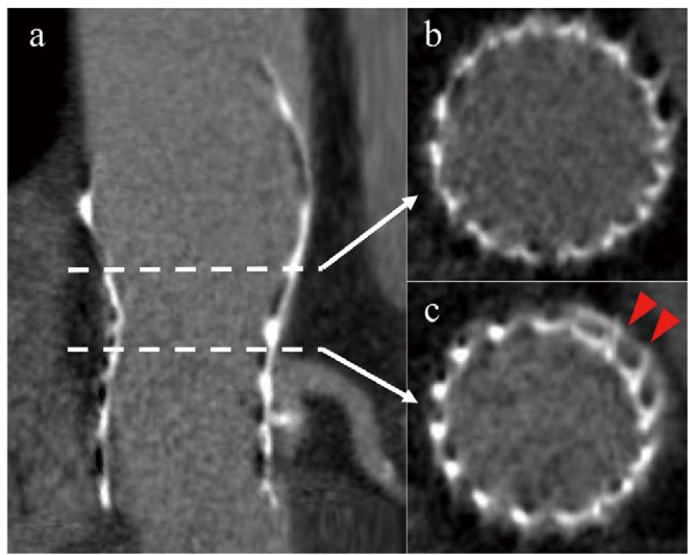

Figure 3. Mechanism and prediction of coronary malperfusion in self-expandable valve (SEV) implantation inside SEV. (A) Schematic diagram in the case of a native sino-tubular junction (STJ)/ascending aortic diameter smaller than the outer diameter of the first SEV. TAVI, transcatheter aortic valve implantation. (B) Multidetector computed tomography (a) stretched aortic root image of a 26-mm CoreValve in patient 4; and (b,c) cross-sectional images at (b) the commissure level, and (c) the STJ level. Red arrowheads, native STJ calcification. There was no room outside the $26-\mathrm{mm}$ CoreValve at the STJ level because the native STJ diameter was smaller than the original outer diameter of the 26-mm CoreValve.

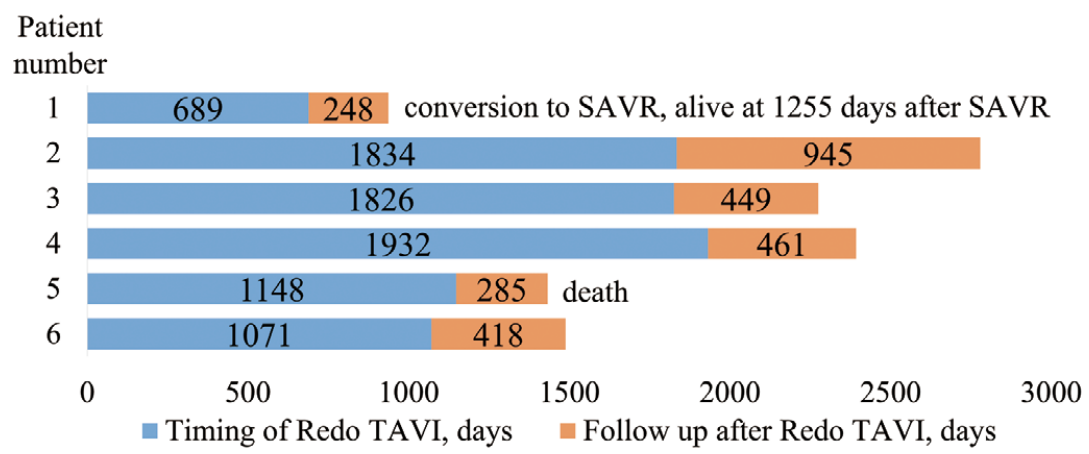

Figure 4. Clinical course after the first transcatheter aortic valve implantation (TAVI). SAVR, surgical aortic valve replacement. 


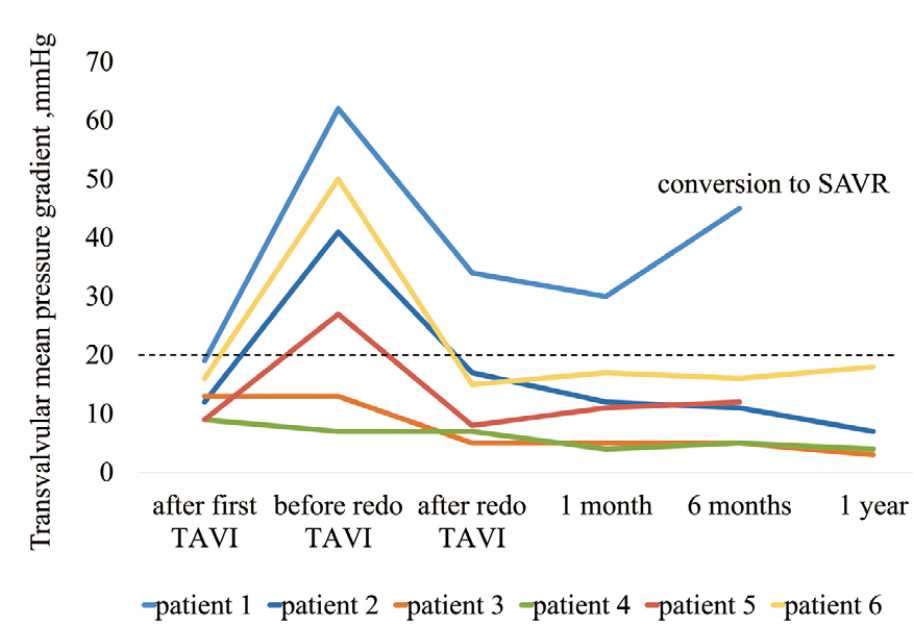

Figure 5. Chronological changes in mean transvalvular pressure gradient. SAVR, surgical aortic valve replacement; TAVI, transcatheter aortic valve implantation.

transvalvular $\mathrm{mPG}$ of $34 \mathrm{mmHg}$ after the redo TAVI (BEV implantation inside BEV). No patients had severe PPM, embolization of the second TAV, or coronary obstruction. In-hospital complications were rare, except for 1 major bleeding complication observed in the patient who underwent concomitant CABG as described earlier. There were no conduction disturbances requiring permanent pacing.

One-year clinical follow-up was achieved in all patients. All patients were alive at 30 days after the procedures, but 1 patient $(16.7 \%)$ died at 285 days after redo TAVI due to a non-cardiovascular cause (aspiration pneumonia). That patient, who had a high residual transvalvular $\mathrm{MPG}$ of $34 \mathrm{mmHg}$ after redo TAVI, underwent surgical aortic valve replacement after 248 days following the redo TAVI because of the recurrence of significant aortic stenosis of the second TAV. At a median follow-up of 455 days (range, 285-1,503 days), 5 of the 6 patients were alive (Figure 4).

\section{Valve Function of Redo TAVI Prosthesis}

Moderate/severe aortic regurgitation after the redo TAVI was not reported; $4(66.7 \%)$ and 2 patients $(33.3 \%)$ had mild and none/trace aortic regurgitation, respectively (Table 2). No regurgitation occurred between the first and second TAV. Redo TAVI reduced the median transvalvular $\mathrm{mPG}$ from $27 \mathrm{mmHg}$ (range, $7-62 \mathrm{mmHg}$ ) before the redo TAVI to $11 \mathrm{mmHg}$ (range, 4-34 $\mathrm{mmHg}$ ). No high residual transvalvular $\mathrm{mPG}$ was observed in the patients who underwent SEV implantation as a second TAV. In all other patients, transvalvular $\mathrm{mPG}$ was $<20 \mathrm{mmHg}$, and it was maintained throughout the 1-year follow-up (Figure 5).

\section{Discussion}

This study demonstrates the following 3 important findings. First, redo TAVI was safely performed with low rates of periprocedural complications and no 30-day mortality, and most patients had good second TAV function throughout the 1-year follow-up. Second, the patients with SEV implantation during the redo TAVI had no high residual transvalvular $\mathrm{mPG}$ after the redo TAVI, although they had a small aortic anatomy. Third, preprocedural MDCT was useful for redo TAVI device size selection and implantation strategy.

The procedural strategy of redo TAVI has not been established and the outcomes of this procedure for TAVSVD have been rarely reported. Barbanti et al investigated the safety and midterm efficacy of redo TAVI in 25 patients with TAV-SVD in the largest international multicenter study to date, and reported no in-hospital mortality and low rates of periprocedural complications such as stroke $(0 \%)$, valve embolization $(0 \%)$, coronary occlusion $(4.0 \%)$, and major vascular complications $(12.0 \%) .{ }^{17}$ The authors observed similar midterm survival (median follow-up, 635 days) and valve function to other recent TAVI (for native aortic valve) series. In a few other case reports, redo TAVI for stenosis of TAV provided an immediate decrease of the transvalvular gradient, no significant complications, and early home discharge, ${ }^{\mathbf{1 8 , 1 9}}$ which is compatible with the present results of no 30-day mortality or stroke, and very low periprocedural complication rates. In addition, most patients had good second TAV function (residual transvalvular $\mathrm{mPG}<20 \mathrm{mmHg}$ ) and no significant paravalvular regurgitation between the first and second TAV throughout the 1-year follow-up except for the 1 patient who died from a non-cardiovascular cause. Therefore, the current study suggests that redo TAVI is a favorable treatment option for TAV-SVD, because those patients who were implanted with TAV were generally at high risk for surgical aortic valve replacement. ${ }^{20}$

All the patients in the present study underwent $23-\mathrm{mm}$ BEV implantation during the first procedure, whereas only half of the European and US patients receive that same BEV size at the first TAVI. ${ }^{17}$ On directly comparison of Asian and European TAVI patients using BEV for native aortic valves, ${ }^{21} 71.9 \%$ of Asian patients received $23-\mathrm{mm}$ devices, whereas only $26.2 \%$ of European patients received 23-mm devices. In the current study, 1 of 2 patients who had the second BEV implanted inside the first BEV had a high residual transvalvular $\mathrm{mPG}$ after redo TAVI. At that time when we started the redo TAVI after approval of the in-hospital ethics committee, BEV was the only approved TAVI prosthesis in Japan. Therefore, we used BEV for redo TAVI in the first 2 cases. It has been shown, however, that a small surgical valve, stenosis-type SVD, and BEV implantation are risk factors for a high residual transvalvular $\mathrm{mPG}$ in TAVI for degenerative surgical bioprosthesis. ${ }^{\mathbf{1 0} 22}$ Therefore, after the approval of SEV in Japan, we used SEV as the second TAV in the other 3 patients 
who had BEV implanted at the first TAVI, and they had no high residual transvalvular $\mathrm{mPG}$ after the redo TAVI. This illustrates the advantage of the supra-annular-designed TAV for the small first TAV commonly used in Japanese patients.

MDCT can be used to assess aortic root anatomy with regard to device size selection and implantation strategy for redo TAVI, similar to the current recommendation for TAVI for native aortic valve stenosis. ${ }^{23}$ Particularly, the device size should be determined according to the stent internal perimeter/diameter of the first TAV to avoid insufficient expansion of the second TAV. This is because MDCT showed that the first TAV were generally much smaller than the label size in the current study. This was also observed in non-TAV-SVD patients. In the present cohort, of 191 consecutive non-TAV-SVD patients who underwent TAVI for tricuspid aortic valve stenosis with a 23-mm TAV (i.e., 23-mm BEV [SAPIEN, SAPIEN XT] and a 26-mm SEV [CoreValve]), 42 patients $(22.0 \%)$ underwent MDCT analysis after the TAVI (although follow-up periods were different) for reasons such as suspected valve thrombosis and coronary malperfusion, and TAV under-expansion, compared with the label size, was observed in all cases; the median stent internal diameter was $19.9 \mathrm{~mm}$ (IQR, 19.2-20.6 mm). Although the data were limited, TAV under-expansion was observed in all of the present patients. Furthermore, $52.4 \%$ of patients who had a $23-\mathrm{mm}$ TAV (23-mm BEV or a 26-mm SEV) implanted during the first TAVI, subsequently had a stent internal diameter $<20.0 \mathrm{~mm}$, implying the need for $20-\mathrm{mm}$ BEV or 23-mm SEV in cases of TAV-SVD. And 1 of the 4 patients $(25 \%)$ with $23-\mathrm{mm}$ BEV implanted at the first TAVI eventually had a smaller device implanted during the redo TAVI (i.e., a 23-mm SEV implanted inside a degenerative 23-mm BEV). Although the data are limited, they support the importance of MDCT-based measurements of the first TAV stent internal diameter prior to redo TAVI for size selection of the second TAV. In addition, specific MDCT assessment is required for SEV implantation inside a degenerative SEV in patients with small aortic anatomy. There has been no case report, to our knowledge, on the risk of coronary malperfusion or method of coronary protection in patients with a small aortic anatomy during this procedure, although the safety and feasibility of SEV implantation inside a degenerative SEV have been demonstrated. ${ }^{18}$ Theoretically, when the STJ/ascending aortic diameter is smaller than the outer diameter of the first SEV at the STJ/ascending aortic level, coronary flow will be disturbed after the second SEV implantation because the leaflets of the first TAV will cover the nitinol struts up to the commissure level, leaving no room for blood flow through the STJ (Figure 3A). We anticipated coronary malperfusion based on preprocedural MDCT in 1 patient with a small STJ, and planned for a 26-mm Evolut R implantation inside a $26-\mathrm{mm}$ CoreValve. In that case, off-pump CABG was performed in addition to redo TAVI via the direct aortic approach, which prevented critical complications such as myocardial infarction and cardiac failure. We also considered surgical aortic valve replacement, but it was already regarded as high-risk at the first TAVI, and the strategy was considered less invasive than a surgical aortic valve replacement in view of the nonrequirement for cardiac arrest. Furthermore, MDCT can rule out leaflet thrombosis of TAV. Leaflet thrombosis is not infrequent in TAV, with reported incidence rates between $16 \%$ and $23 \% .^{15,24,25}$ Unlike in the case of SVD, leaflet thrombosis can be treated with anticoagulant; thus, precise detection is necessary. The aforementioned findings indicate the importance of preprocedural MDCT in redo TAVI.

In the present study the incidence of redo TAVI was $1.0 \%$ during a median follow-up period of 602 days, although follow-up period differed between the patients. Notably, the patients who underwent redo TAVI had a high prevalence of chronic dialysis. One patient with dialysis underwent surgical aortic valve replacement due to the recurrence of significant aortic stenosis of the second TAV in $\leq 1$ year, which is compatible with reports indicating that chronic renal failure is a risk factor for SVD. ${ }^{26,27}$ Renal failure can accelerate the progression of TAV degeneration, similar to the native aortic valve, mainly due to reactive hyperparathyroidism and resultant hypercalcemia. ${ }^{28,29}$ This emphasizes the importance of carrying out a large study with a long-term follow-up on the efficacy of TAVI in dialysis patients. Currently, a prospective clinical trial of TAVI for Japanese dialysis patients is ongoing (Clinical Trials.gov: NCT02903420).

\section{Study Limitations}

This study had some limitations. First, this was a singlecenter observational study with a limited number of patients. To the best of our knowledge, however, this is the first study to report the periprocedural and clinical outcomes of redo TAVI for the treatment of TAV-SVD in Japanese patients. Second, this study was also the first to show TAV under-expansion compared with the label size in patients who underwent redo TAVI. We could not, however, compare the stent internal diameter immediately after the first TAVI with that before the redo TAVI, because we did not routinely perform MDCT immediately after the TAVI due to the high prevalence of chronic kidney disease. Furthermore, the MDCT data for non-TAV-SVD patients after TAVI were limited. Therefore, the relationship between TAV under-expansion and TAV-SVD could not be clarified, and further studies are required to elucidate this relationship.

\section{Conclusions}

Redo TAVI for TAV-SVD appears safe and feasible, but specific strategies based on MDCT assessment and device selection will be important for better outcomes in Japanese patients. Future large multicenter studies are necessary to confirm the present results.

\section{Acknowledgments}

We gratefully thank Edwards Lifesciences and Medtronic for providing the redo TAVI devices.

\section{Disclosures}

Y. Sakata and Y. Sawa received research grants from Edwards Lifesciences and scholarship funds from Edwards Lifesciences and Medtronic. The other authors declare no conflicts of interest.

\section{References}

1. Makkar RR, Fontana GP, Jilaihawi H, Kapadia S, Pichard AD, Douglas PS, et al. Transcatheter aortic-valve replacement for inoperable severe aortic stenosis. $N$ Engl J Med 2012; 366: 1696-1704.

2. Smith CR, Leon MB, Mack MJ, Miller DC, Moses JW, Svensson LG, et al. Transcatheter versus surgical aortic-valve 
replacement in high-risk patients. $N$ Engl J Med 2011; 364: 2187-2198.

3. Leon MB, Smith CR, Mack MJ, Makkar RR, Svensson LG, Kodali SK, et al. Transcatheter or surgical aortic-valve replacement in intermediate-risk patients. $N$ Engl J Med 2016; 374: $1609-1620$.

4. Arora S, Vaidya SR, Strassle PD, Misenheimer JA, Rhodes JA, Ramm CJ, et al. Meta-analysis of transfemoral TAVR versus surgical aortic valve replacement. Catheter Cardiovasc Interv 2018; 91: 806-812.

5. Kapadia SR, Leon MB, Makkar RR, Tuzcu EM, Svensson LG, Kodali S, et al. 5-Year outcomes of transcatheter aortic valve replacement compared with standard treatment for patients with inoperable aortic stenosis (PARTNER 1): A randomised controlled trial. Lancet 2015; 385: 2485-2491.

6. Mack MJ, Leon MB, Smith CR, Miller DC, Moses JW, Tuzcu EM, et al. 5-Year outcomes of transcatheter aortic valve replacement or surgical aortic valve replacement for high surgical risk patients with aortic stenosis (PARTNER 1): A randomised controlled trial. Lancet 2015; 385: 2477-2484.

7. Barbanti M, Petronio AS, Ettori F, Latib A, Bedogni F, De Marco F, et al. 5-Year outcomes after transcatheter aortic valve implantation with CoreValve prosthesis. JACC Cardiovasc Interv 2015; 8: 1084-1091.

8. Yoon SH, Ohno Y, Araki M, Barbanti M, Lin MS, Ahn JM, et al. Comparison of aortic root anatomy and calcification distribution between Asian and Caucasian patients who underwent transcatheter aortic valve implantation. Am J Cardiol 2015; 116: $1566-1573$.

9. Sawa Y, Takayama M, Mitsudo K, Nanto S, Takanashi S, Komiya $\mathrm{T}$, et al. Clinical efficacy of transcatheter aortic valve replacement for severe aortic stenosis in high-risk patients: The PREVAIL JAPAN trial. Surg Today 2015; 45: 34-43.

10. Dvir D, Webb JG, Bleiziffer S, Pasic M, Waksman R, Kodali S, et al. Transcatheter aortic valve implantation in failed bioprosthetic surgical valves. JAMA 2014; 312: 162-170.

11. Webb JG, Mack MJ, White JM, Dvir D, Blanke P, Herrmann HC, et al. Transcatheter aortic valve implantation within degenerated aortic surgical bioprostheses: PARTNER 2 Valve-in-Valve Registry. J Am Coll Cardiol 2017; 69: 2253-2262.

12. Dvir D, Bourguignon T, Otto CM, Hahn RT, Rosenhek R, Webb JG, et al. Standardized definition of structural valve degeneration for surgical and transcatheter bioprosthetic aortic valves. Circulation 2018; 137: 388-399.

13. Kappetein AP, Head SJ, Genereux P, Piazza N, van Mieghem $\mathrm{NM}$, Blackstone EH, et al. Updated standardized endpoint definitions for transcatheter aortic valve implantation: The Valve Academic Research Consortium-2 consensus document (VARC2). Eur J Cardiothorac Surg 2012; 42: S45-S60.

14. Zoghbi WA, Chambers JB, Dumesnil JG, Foster E, Gottdiener JS, Grayburn PA, et al. Recommendations for evaluation of prosthetic valves with echocardiography and Doppler ultrasound: A report From the American Society of Echocardiography's Guidelines and Standards Committee and the Task Force on Prosthetic Valves, developed in conjunction with the American College of Cardiology Cardiovascular Imaging Committee, Cardiac Imaging Committee of the American Heart Association, the European Association of Echocardiography, a registered branch of the European Society of Cardiology, the Japanese Society of Echocardiography and the Canadian Society of Echocardiography, endorsed by the American College of Cardiology Foundation, American Heart Association, European Association of Echocardiography, a registered branch of the European Society of Cardiology, the Japanese Society of Echocardiography, and Canadian Society of Echocardiography. J Am Soc Echocardiogr 2009; 22: 975-1014; quiz 1082-1084.

15. Makkar RR, Fontana G, Jilaihawi H, Chakravarty T, Kofoed $\mathrm{KF}$, De Backer O, et al. Possible subclinical leaflet thrombosis in bioprosthetic aortic valves. $N$ Engl J Med 2015; 373: 2015-2024.

16. Jilaihawi H, Asch FM, Manasse E, Ruiz CE, Jelnin V, Kashif M, et al. Systematic CT methodology for the evaluation of subclinical leaflet thrombosis. JACC Cardiovasc Imaging 2017; 10: 461 -470.

17. Barbanti M, Webb JG, Tamburino C, Van Mieghem NM, Makkar RR, Piazza N, et al. Outcomes of redo transcatheter aortic valve replacement for the treatment of postprocedural and late occurrence of paravalvular regurgitation and transcatheter valve failure. Circ Cardiovasc Interv 2016; 9: pii: e003930.

18. Hammerstingl C, Nickenig G, Grube E. Treatment of a degenerative stenosed CoreValve $(\mathrm{R}))$ aortic bioprosthesis by transcatheter valve-in-valve insertion. Catheter Cardiovasc Interv 2012; 79: $748-755$.

19. Sinning JM, Vasa-Nicotera M, Werner N, Zimmer S, Mellert F, Welz A, et al. CoreValve degeneration with severe transvalvular aortic regurgitation treated with valve-in-valve implantation. JACC Cardiovasc Interv 2014; 7: e71-e72.

20. Hein R, Abdel-Wahab M, Sievert H, Kuck KH, Voehringer M, Hambrecht R, et al. Outcome of patients after emergency conversion from transcatheter aortic valve implantation to surgery. EuroIntervention 2013; 9: 446-451.

21. Watanabe Y, Hayashida K, Takayama M, Mitsudo K, Nanto S, Takanashi S, et al. First direct comparison of clinical outcomes between European and Asian cohorts in transcatheter aortic valve implantation: The Massy study group vs. the PREVAIL JAPAN trial. J Cardiol 2015; 65: 112-116.

22. Ochiai T, Yoon SH, Sharma R, Miyasaka M, Nomura T, Rami $\mathrm{T}$, et al. Outcomes of self-expanding vs. balloon-expandable transcatheter heart valves for the treatment of degenerated aortic surgical bioprosthese: A propensity score-matched comparison. Circ J 2018; 82: 2655-2662.

23. Casset C, Jankowski A, Bertrand B, Saunier C, Piliero N, Rodiere M, et al. Evaluation of imaging strategy to optimize and improve outcome of transcatheter aortic valvular implantation. Am J Cardiol 2017; 120: 1633-1638.

24. Ruile P, Minners J, Breitbart P, Schoechlin S, Gick M, Pache G, et al. Medium-term follow-up of early leaflet thrombosis after transcatheter aortic valve replacement. JACC Cardiovasc Interv 2018; 11: 1164-1171.

25. Marwan M, Mekkhala N, Goller M, Rother J, Bittner D, Schuhbaeck A, et al. Leaflet thrombosis following transcatheter aortic valve implantation. J Cardiovasc Comput Tomogr 2018; 12: $8-13$.

26. Okada N, Tajima K, Takami Y, Kato W, Fujii K, Hibino M, et al. Valve selection for the aortic position in dialysis patients. Ann Thorac Surg 2015; 99: 1524-1531.

27. Iyer A, Malik P, Prabha R, Kugathasan G, Kuteyi O, Marney $\mathrm{L}$, et al. Early postoperative bioprosthetic valve calcification. Heart Lung Circ 2013; 22: 873-874.

28. Francis CM, Ormerod O, Raine AEG, Yver L, Jaulin JP, Turpin $\mathrm{Y}$, et al. Rapidly progressive aortic stenosis associated with hyperparathyroidism in renal failure. Lancet 1988; 331: 246-247.

29. Kume T, Kawamoto T, Akasaka T, Watanabe N, Toyota E, Neishi Y, et al. Rate of progression of valvular aortic stenosis in patients undergoing dialysis. J Am Soc Echocardiogr 2006; 19: 914-918. 